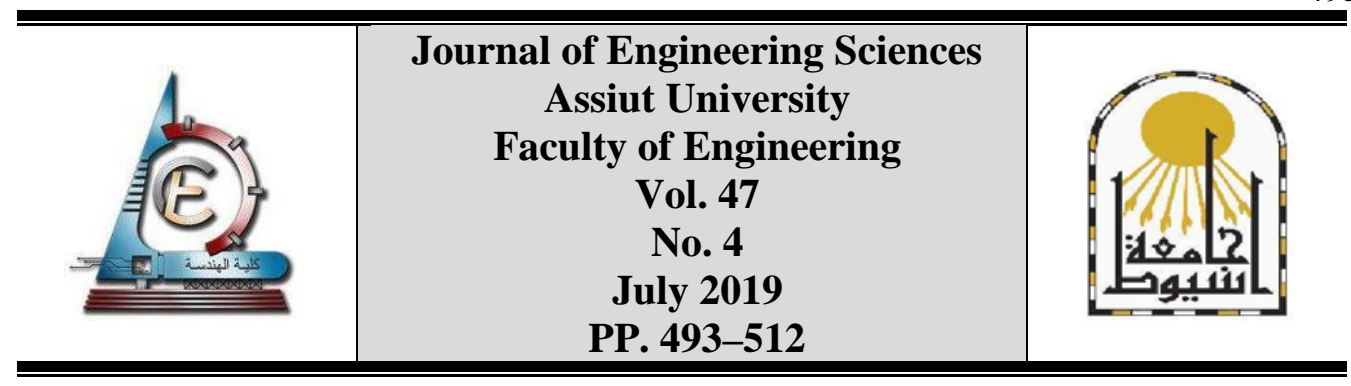

\title{
SIMULATION MODELING OF A DUAL FUEL (NATURAL GAS- DIESEL) ENGINE USING EARLY DIRECT INJECTION TECHNIQUE OF NATURAL GAS
}

\author{
Saleh Abo-Elfadl, Muhammad Abdulmoez, A. M. Nassib \\ Mechanical Engineering Department, Assiut University, Assiut (71516), Egypt.
}

Received 27 January 2019; Accepted 15 March 2019

\begin{abstract}
The research for alternative fuels increased rapidly to mitigate the pollution problems resulting from using conventional fuels in internal combustion engines. Natural gas (NG) appears the most promising alternative due to its low prices and availability around the world.

In this paper, a two-zone, zero-dimensional (0-D) model for the simulation of dual fuel NGdiesel engine is developed to study the performance of the engine with a proposed technique of NG early direct injection. The model is composed of several sub-models that are based on semiempirical formulas. NG is modeled as being directly injected at the beginning of the compression stroke. The model is applied to study the performance of HELWAN M-114 diesel engine using dual fuel of NG and diesel fuels as a case study.

The results indicate that using NG early direct injection technique (EDI) results in increasing the volumetric efficiency and hence the brake power of the engine compared to the intake manifold induction (IMI) of NG with air through the intake manifold. The percentage increase in brake power is $8.7 \%$ at NG mass ratio in the total fuel (the supplement ratio (SR)) of $90 \%$ at full load. To evaluate the proposed technique, results obtained by varying the engine load and the SR. Results indicate that the slow burning rate of NG results in decrease in the brake thermal efficiency by $3.5 \%$ and increases in brake specific fuel consumption with a percentage of $10.2 \%$ at $90 \% \mathrm{SR}$ and full load. However, a great advantage of increasing the SR is the reduction in $\mathrm{NO}_{\mathrm{x}}$ and soot emissions particularly at high engine loads where they were reduced with percentages of $28.6 \%$ and $86 \%$, respectively at $90 \%$ SR and full load condition.
\end{abstract}

Keywords: dual fuel engine, direct injection, natural gas, supplement ratio

Nomenclature

\section{Symbols}

A Area $\left(m^{2}\right)$

$B P \quad$ Brake power $(k W)$

$C_{p} \quad$ Constant pressure specific heat

\section{Greek Symbols}

$\eta_{\text {bth }} \quad$ Brake thermal efficiency (\%)

$\eta_{\mathrm{v}} \quad$ Volumetric efficiency (\%)

$\theta \quad$ Crank angle (degrees)

* Corresponding author.

Email address: m_abdulmoez@aun.edu.eg 


\begin{tabular}{|c|c|c|c|}
\hline \multirow[b]{2}{*}{$C_{v}$} & \multicolumn{3}{|l|}{$(\mathrm{kJ} /(\mathrm{kg} \cdot \mathrm{K}))$} \\
\hline & $\begin{array}{l}\text { Constant volume specific heat } \\
(\mathrm{kJ} /(\mathrm{kg} . \mathrm{K}))\end{array}$ & $\mu$ & Dynamic viscosity $\left(N . s / m^{2}\right)$ \\
\hline$e$ & Specific internal energy $(\mathrm{kJ} / \mathrm{kg})$ & $\rho$ & Density $\left(\mathrm{kg} / \mathrm{m}^{3}\right)$ \\
\hline$h$ & Specific enthalpy $(\mathrm{kJ} / \mathrm{kg})$ & $\tau_{i d}$ & Ignition delay period ( $\mathrm{ms}$ ) \\
\hline$k$ & Specific heat ratio & $\phi$ & Equivalence ratio \\
\hline$m$ & Mass $(k g)$ & \multicolumn{2}{|c|}{ Subscripts } \\
\hline$p$ & Pressure $(k P a)$ & $b$ & Burned \\
\hline$Q, q$ & $\begin{array}{l}\text { Heat transfer }(k J) \text {, heat transfer } \\
\text { flux }\left(k J / \mathrm{m}^{2}\right)\end{array}$ & d & Diesel \\
\hline$R e$ & Reynolds number & $\mathrm{db}$ & Burned diesel \\
\hline$S_{p}$ & Mean piston speed $(\mathrm{m} / \mathrm{s})$ & $\mathrm{dt}$ & Total diesel \\
\hline$T$ & Temperature $(K)$ & ex & Exhaust \\
\hline$V$ & $\begin{array}{l}\text { Instantaneous cylinder volume } \\
\left(\mathrm{m}^{3}\right)\end{array}$ & in & Intake \\
\hline$x$ & Mass fraction & inj & Injection \\
\hline \multicolumn{2}{|c|}{ Abbreviations } & $\max$ & Maximum \\
\hline bsfc & $\begin{array}{l}\text { Brake specific fuel consumption } \\
(\mathrm{g} / \mathrm{kW} \cdot \mathrm{h})\end{array}$ & s & Soot \\
\hline EDI & Early direct injection & sf & Soot formation \\
\hline fmep & $\begin{array}{l}\text { Friction mean effective pressure } \\
(\mathrm{kPa})\end{array}$ & so & Soot Oxidation \\
\hline IMI & Intake manifold induction & & Valve \\
\hline IVC & Intake valve closure & \multicolumn{2}{|c|}{ Superscripts } \\
\hline LHV & Lower heating value $(\mathrm{kJ} / \mathrm{kg})$ & & $\begin{array}{l}\text { Derivative with respect to time } \\
(d / d t)\end{array}$ \\
\hline
\end{tabular}

\section{Introduction}

The world energy demand increases rapidly every year due to the growth in population as the energy consumption increases by $1.7 \%$ per year for the last ten years [1]. Therefore, there is a significant increase in crude oil consumption with an accompanying deterioration in air quality which forces the engines manufacturers to search for low emission alternative fuels. The most promising alternative fuel is NG due to its low emissions level and its availability at lower prices around the world compared to the other alternatives [2,3].

Dual fuel engines which use NG and diesel are widely used as they achieve the environmental requirements where the combustion of the gaseous fuel produces low emissions relative to the use of diesel fuel only. In a common approach, which will be conventionally called intake manifold induction (IMI) technique in this article, NG is inducted to the engine through the intake manifold with the air forming a homogenous mixture. Near the end of the compression stroke, a certain amount of diesel fuel, called pilot fuel, is directly injected to initiate the combustion since NG does not self-ignite at normal diesel engine operating conditions because of its high autoignition temperature (540-560 ${ }^{\circ} \mathrm{C}$ [4]). The advantages of this method include the simplicity of application and the good mixing between NG and air which improves the combustion. The major drawback of this approach is the low brake power of the engine due to the reduction in the volumetric efficiency. Some of the air in the intake manifold is displaced by NG. This results in a reduction of the inlet air mass through the intake stroke and, therefore, the volumetric efficiency is reduced [5]. Another drawback is the escape of some amount of NG through the exhaust valve during the overlap period. Moreover, NG has a low laminar flame speed 
especially at high pressures where it has a value about $7 \mathrm{~cm} / \mathrm{s}$ at stoichiometric condition and at the average cylinder pressure of the combustion process [6]. Therefore, the engine should produce enough air swirl motion to carry the flame front through the cylinder content.

In order to avoid these drawbacks, another approach is to directly inject NG inside the engine cylinder through the compression stroke before the pilot fuel injection. Direct injection of NG in dual fuel engines using high pressure direct injection technology has been investigated in many studies [7-10]. Using this technology, both NG and diesel are directly injected through the same injector at high pressure (200-300 bar) [11]. Near top dead center (TDC), pilot diesel is first injected with a small amount (5\% on energy basis at full load) followed by the injection of NG. This generates a stratified NG-air mixture with nearly stoichiometric mixture near the injector nozzle and lean mixture in the remaining of the cylinder due to the high injection pressure [12]. The benefits include improvements in thermal efficiency through increasing the flame speed of NG resulting from the combustion of locally stoichiometric NG-air mixture [13]. However, the main drawbacks of this method include the increased complexity of the injection system due to the high injection pressure and the increase in soot emissions due to the presence of rich mixture zones $[14,15]$.

Engine simulations are valuable tools for evaluating the performance and emission parameters. Two types of simulation models are used for internal combustion engines studies: 0-D models and multi-dimensional models. Multi-dimensional models provide more detailed results but require high computational power and long calculation time. On the other hand, 0-D models provide relatively accurate results with lower computational power and time requirements.

Many theoretical analyses using 0-D modeling for the NG engine performance were carried out. Mansour et al. [16] developed a 0-D simulation model for investigating the performance and emissions of a dual fuel NG-diesel engine. They used a detailed chemical kinetics reaction mechanism including 79 reactions for predicting pressure, temperature and species concentrations variations through the engine cylinder. The results of the study have a reasonable agreement with the experimental measurements. Hountalas and Papagiannakis [17] suggested a numerical simulation model of a dual fuel NG-diesel engine based on two zone combustion model. The model provides good prediction for the pressure-time diagram of the engine cylinder under different SRs of NG. They more developed the model in $[18,19]$ where the results illustrated that using $\mathrm{NG}$ decreases both $\mathrm{NO}_{\mathrm{x}}$ and soot emissions compared with diesel operation. Soylu and Gerpen [20] developed an empirical equation for the burning rate of the NG based on Wiebe function where an acceptable agreement of the cylinder pressure-time diagram at different equivalence ratios was achieved. The constants of the Wiebe function are replaced by empirical functions based on the equivalence ratio. Another 0-D simulation model having a detailed chemical reaction mechanism was developed by Zheng and Caton [21]. They used a single-zone model coupled with Chemkin software with 53 species and 325 reactions to model a homogeneous charge compression ignition engine. The results indicate that the engine speed greatly affect the temperature at TDC. Mikulski et al. [22] proposed a 0-D simulation model of a dual fuel compression ignition engine. They used first order macro reactions for the NG components. The results have reasonable agreement with the experimental measurements. Tirkey et al. [23] developed a simulation model for a multi-cylinder engine fueled with NG. The model includes a combustion model based on turbulent flame propagation analysis and two zones combustion chamber content. The flow through the intake and exhaust manifolds was 
modeled as one-dimensional flow by the characteristics method. The results of the model are compatible with the experimental results.

In this article, the performance of NG-diesel engine is investigated with a proposed technique of early NG direct injection (EDI). The injection of NG is chosen to be after intake valve closure. This technique combines the benefits of improved NG-air mixing through the compression stroke and increased volumetric efficiency by direct injection. Moreover, low injection pressure can be selected to ensure more simplicity and safety requirements for the injection system. A 0-D, two-zone combustion model is developed for evaluating this technique which consists of several sub-models which are described in the following section.

\section{The mathematical model description}

\subsection{General assumptions}

In the mathematical model, the air charge through the intake stroke and the residual gas fraction from the previous cycle are assumed a homogenous mixture through the intake stroke. The injected NG at the beginning of the compression stroke is assumed as a homogenous mixture with the cylinder charge through the compression stroke. As the pilot diesel fuel is injected it takes a delay time till starting of combustion and ignites the NG. During the combustion process, the engine cylinder is assumed as two zones; each zone has a homogenous composition and temperature at each instant while the two zones have the same pressure value. The first zone is the unburned zone which contains the air and the NG. The second zone is the burned zone where the combustion products are presented. After combustion is completed, only the combustion products are presented through the remainder part of the power stroke and the exhaust stroke. The combustion products are assumed eleven components which are: $\mathrm{CO}_{2}$, $\mathrm{CO}, \mathrm{O}_{2}, \mathrm{O}, \mathrm{N}_{2}, \mathrm{~N}, \mathrm{NO}, \mathrm{H}_{2}, \mathrm{H}, \mathrm{OH}$ and $\mathrm{H}_{2}$ [24]. The percentages of the combustion products components are calculated according to the chemical equilibrium assumption [24].

\subsection{The thermodynamic properties model}

The thermodynamic properties for the in-cylinder species are calculated using the coefficients from the NASA equilibrium program [25]. These coefficients are for the leastsquares curve fit to the data in JANAF thermodynamic properties tables. The molar specific heat under constant pressure $\left(\bar{C}_{p}\right)$ and the molar enthalpy $(\bar{h})$ are calculated using these coefficients as follows:

$$
\begin{aligned}
& \frac{\bar{C}_{p i}}{\bar{R}}=a_{i 1}+a_{i 2} T+a_{i 3} T^{2}+a_{i 4} T^{3}+a_{i 5} T^{4} \\
& \frac{\bar{h}_{i}}{\bar{R} T}=a_{i 1}+\frac{a_{i 2}}{2} T+\frac{a_{i 3}}{3} T^{2}+\frac{a_{i 4}}{4} T^{3}+\frac{a_{i 5}}{5} T^{4}+\frac{b_{i 1}}{T}
\end{aligned}
$$

Where: $a_{i 1}$ to $a_{i 5}$ and $b_{i 1}$ are the coefficients for $i$ species given in [25]. The average values for thermodynamic properties of the cylinder contents can be calculated by the relations of ideal gas mixtures.

\subsection{Engine friction model}

The engine friction is calculated according to the correlation which discussed by Chen and Flynn [26,27]. The correlation gives the fmep form as follows: 
fmep $=40+0.005 \times p_{\max }+9 \times S_{p}+0.09 \times S_{p}^{2}$

\subsection{Heat transfer model}

The instantaneous heat transfer rate between the cylinder charge and the surrounding surfaces (cylinder wall, piston crown surface and the cylinder head surface) is calculated according to Lawton model [28]:

$q_{w}=\left(\frac{\hat{k}}{d}\right)\left\{\hat{a} R e^{b}\left(T-T_{w}\right)-2.75 C_{1} T_{w}\right\}+\hat{c} \sigma\left(T^{4}-T_{w}^{4}\right)$

Where: $C_{1}=(k-1) \frac{d V}{V}\left(\frac{d^{3}}{\alpha_{o} S_{p}}\right)^{1 / 2}$ and $k=\frac{9 k-5}{4} \mu C_{v}$. Through the combustion process, the cylinder temperature is taken as the bulk average temperature of the burned and unburned zones.

\subsection{Fuels injection models}

The mass flow rate of injected diesel fuel is simulated as a function of the total mass according to the following equation [29]:

$\left(\frac{\dot{m}_{d}}{m_{d t}}\right)=\left(\frac{\pi}{2 \Delta \theta_{\text {inj }}}\right) \sin \left(\frac{\pi\left(\theta-\theta_{o}\right)}{\Delta \theta_{\text {inj }}}\right) \dot{\theta}$

Where: $\theta_{\mathrm{o}}$ is the crank angle at the start of injection and $m_{d t}$ is the total injected mass of diesel fuel. The mass flow rate of injected NG is simulated as a chocked flow through a singlehole injector. The chocking condition is practically chosen for NG injection since it ensures stable injection [15]. The injection pressure of NG is chosen to be equal 10 bar since this value can maintain a critical pressure ratio through the injector nozzle for the selected injection timing, which is equal to IVC, and engine loads. The mass flow rate of NG is given by [30]:

$$
\dot{m}_{N G}=C_{D} A_{n} P_{i n j} \sqrt{\frac{k M}{R T}\left(\frac{2 k}{k-1}\right)^{\frac{k+1}{k-1}}}
$$

Where: $C_{D}$ is the discharge coefficient through the nozzle and $A_{n}$ is the nozzle area.

\subsection{The Ignition delay model}

The correlation developed by $\mathrm{Xu}$ et al. [31] for dual fuel engines is used which gives the ignition delay as:

$\tau_{i d}=2.4 \phi_{p d}^{-0.2} p^{-1.02} \exp \left(\frac{E_{a}}{\bar{R} T}\right)$

Where: $\phi_{p d}=\frac{m_{d} / m_{O_{2}}}{0.328}$ and is called the pseudo-diesel equivalence ratio and the value of $\frac{E_{a}}{\bar{R}}$ is taken equal to $2100 \mathrm{~K}$ as in [31]. 


\subsection{The heat release model}

The NG combustion rate is calculated according to the modified Wiebe function by Mansour et al. [16] for a wide range of engine speeds and loads. The function has the following formula:

$\frac{d m_{N G b}}{d \theta}=\frac{1}{\Delta \theta_{T}} A B \hat{\theta}^{B-1} \exp \left(-A \hat{\theta}^{B}\right)$

Where: $\hat{\theta}=\frac{\theta-\theta_{c}}{\Delta \theta_{T}}, \theta_{c}$ is the crank angle at the start of combustion, and $\Delta \theta_{T}$ is the combustion duration. The values of $\mathrm{A}, \mathrm{B}$, and $\Delta \theta_{T}$ are illustrated for different engine speeds and loads in [16]. The pilot fuel (diesel fuel) burning rate is calculated according to Watson et al. correlation as follows [32]:

$\frac{m_{d b}(\dot{\theta})}{m_{d t}}=\beta f_{1}+(1-\beta) f_{2}$

Where:

$f_{1}=1-\left(1-\dot{\theta}^{K_{1}}\right)^{K_{2}}$

$f_{2}=1-\exp \left(-K_{3} \dot{\theta}^{K_{4}}\right)$

$\dot{\theta}=\left(\theta-\theta_{c}\right) / \Delta \theta_{b}$

$\beta=1-\left(a \phi^{b} / \tau_{i d}^{c}\right)$

The values of $K_{1}, K_{2}, K_{3}, K_{4}, a, b$ and $c$ are given in [32].

\subsection{The pressure and temperature relationships}

The cylinder charge through the intake, compression and exhaust processes are assumed single zone (homogenous mixture) and the pressure and temperature variations through these processes are calculated according to the following equations [33]:

$$
\begin{aligned}
& \dot{T}=\frac{1}{m C_{v}}\left\{\dot{Q}-p \dot{V}+\sum\left(\dot{m}_{i n} h_{i n}-\dot{m}_{e x} h_{e x}\right)-e \dot{m}-m \sum_{i} e_{i} \dot{x}_{i}\right\} \\
& \dot{p}=\frac{\rho}{\partial \rho / \partial p}\left\{\frac{\dot{m}}{m}+\sum_{i} \frac{R_{i} \dot{x}_{i}}{R}-\frac{\dot{V}}{V}-\frac{\partial \rho / \partial T}{\rho} \dot{T}\right\}
\end{aligned}
$$

Where: $i$ denotes the number of species in the cylinder charge. Through the combustion process the cylinder is assumed to be consisted of two zones, burned zone and unburned zone. The cylinder charge in each zone is assumed homogenous and the zones have different temperatures and the same pressure value. The pressure and temperature variations through these zones are calculated according to the following equations [23]: 
$\dot{T}_{u}=\frac{1}{m_{u} C_{p, u}}\left(V_{u} \dot{P}+\dot{Q}_{u}\right)$

$\dot{T}_{b}=\frac{p}{m_{b} R_{b}}\left\{\dot{V}-\left(\frac{R_{b} T_{b}}{p}-\frac{R_{u} T_{u}}{p}\right) \dot{m}_{b}+\left(\frac{V}{p}-\frac{R_{u} V_{u}}{p C_{p, u}}\right) \dot{p}-\frac{R_{u}}{p C_{p, u}} \dot{Q}_{u}\right\}$

$\dot{p}=-\frac{1}{X^{o}}\left\{\left(1+\frac{C_{v, b}}{R_{b}}\right) p \dot{V}+\left(\left(e_{b}-e_{u}\right)-C_{v, b}\left(T_{b}-\frac{R_{u}}{R_{b}} T_{u}\right)\right) \dot{m}_{b}+Y^{o} \dot{Q}_{u}-\dot{Q}\right\}$

Where: $X^{o}=Y^{o} V_{u}+\frac{C_{v, b}}{R_{b}} \quad$ and $\quad Y^{o}=\frac{C_{v, u}}{C_{p, b}}-\frac{C_{v, b} R_{u}}{C_{p, u} R_{b}}$. The average cylinder temperature can be calculated by energy balance as follows [34]:

$T=\frac{m_{u} C_{v, u} T_{u}+m_{b} C_{v, b} T_{b}}{m_{c y l} C_{v, c y l}}$

Where: $m_{u}, m_{b}$ and $m_{c y l}$ are the instantaneous masses of the unburned zone, burned zone and the total cylinder contents. $C_{v, u}, C_{v, b}$ and $C_{v, c y l}$ are the corresponding instantaneous specific heats.

\subsection{NOx formation mechanism}

The nitric oxides $\left(\mathrm{NO}_{\mathrm{x}}\right)$ formation rate is calculated according to the extended Zeldovich mechanism which described in [35]. The mechanism consists of the following reactions:

$\left.\begin{array}{rl}O+N_{2} \leftrightarrow N O+N \\ N+O_{2} \leftrightarrow N O+O \\ N+O H \leftrightarrow N O+H\end{array}\right\}$

Assuming equilibrium values of $\mathrm{O}, \mathrm{O}_{2}, \mathrm{OH}, \mathrm{H}$ and $\mathrm{N}_{2}$, NO formation rate can be calculated by the following equation:

$\frac{d}{d t}[N O]=2 k_{1 f}[O]_{e}\left[N_{2}\right]_{e}\left\{\frac{1-[N O]^{2} /\left(K_{12}\left[O_{2}\right]_{e}\left[N_{2}\right]_{e}\right)}{1+k_{1 b}[N O] /\left(k_{2 f}\left[O_{2}\right]_{e}+k_{3 f}[O H]_{e}\right)}\right\}$

Where: $\mathrm{K}_{12}=\left(\mathrm{k}_{1 \mathrm{f}} / \mathrm{k}_{1 \mathrm{~b}}\right) /\left(\mathrm{k}_{2 \mathrm{f}} / \mathrm{k}_{2 \mathrm{~b}}\right)$, subscripts 1,2 and 3 refer to the three reactions in equation (20), subscripts $f$ and $b$ refer to forward and backward reactions, respectively, subscript $e$ refers to thermodynamic equilibrium and the square brackets [ ] denote concentration in mole $/ \mathrm{cm}^{3}$. The forward and backward rate constants are given by (in $\mathrm{cm}^{3} /($ mole. $\mathrm{s})$ ):

$$
\left.\begin{array}{c}
k_{1 f}=7.6 \times 10^{13} \exp \left(-38000 / T_{b}\right) \\
k_{1 b}=1.6 \times 10^{13} \\
k_{2 f}=6.4 \times 10^{9} T_{b} \exp \left(-3150 / T_{b}\right) \\
k_{2 b}=1.5 \times 10^{9} T_{b} \exp \left(-19500 / T_{b}\right) \\
k_{3 f}=4.1 \times 10^{13}
\end{array}\right\}
$$




\subsection{Soot formation and oxidation mechanism}

The soot formation in this model is assumed to be formed by the diesel fuel only and the formed soot from the NG is neglected since NG only forms soot at rich mixtures [36] and the diesel engine operates at lean mixture conditions for the whole load range. The soot formation and oxidation are calculated according to the Hiroyasu et al. model [37]. The model consists of two equations describing the formation and oxidation rates and the net soot rate is the difference between the two equations as follows:

$$
\begin{gathered}
\dot{m}_{s}=\dot{m}_{s f}-\dot{m}_{s o} \\
\dot{m}_{s f}=A_{s f} m_{d v} p^{0.5} \exp \left(-E_{s f} / \bar{R} T_{b}\right) \\
\dot{m}_{s o}=A_{s o} m_{s} \frac{p_{O_{2}}}{p} p^{1.8} \exp \left(-E_{s o} / \bar{R} T_{b}\right)
\end{gathered}
$$

Where: $m_{d v}$ is the mass of diesel vapor, $E_{s f}=12500 \mathrm{cal} / \mathrm{mole}, p$ is the cylinder pressure in (atm), and $E_{s o}=4100 \mathrm{cal} / \mathrm{mole}$. The adjustable parameters $A_{s f}$ and $A_{s o}$ are taken equal to $10^{-4}$ and 40000 , respectively [38].

\subsection{Flow rate through valves}

The flow rates through the valves are usually calculated by the equations of isentropic compressible fluid flow through a nozzle. To account for the real flow, a discharge coefficient, which is experimentally determined, is added to the equations [29]. These equations relate the mass flow rate with the stagnation pressure and temperature upstream of the valve $\left(p_{u s}, T_{u s}\right)$ and the static pressure downstream of the valve $\left(p_{d s}\right)$. For the inlet flow through the intake valve, $p_{u s}=p_{i m}, T_{u s}=T_{i m}$, and $p_{d s}=p_{c y l}$. For the exit flow through the exhaust valve $p_{u s}=$ $p_{c y l}, T_{u s}=T_{c y l}$, and $p_{d s}=p_{e m}$. The subscripts $c y l$, im, and em denote cylinder, intake manifold, and exhaust manifold respectively. The mass flow rates are calculated as follows [35]:

- For subsonic flow where: $\frac{p_{d s}}{p_{u s}}<\left(\frac{2}{k+1}\right)^{\frac{k}{k-1}}$

$\dot{m}=C_{D} A_{v} p_{u s} \sqrt{\left(\frac{2 k}{(k-1) R T_{u s}}\right)\left(\frac{p_{d s}}{p_{u s}}\right)^{\frac{2}{k}}\left(1-\left(\frac{p_{d s}}{p_{u s}}\right)^{\frac{k-1}{k}}\right)}$

- $\quad$ For sonic flow where: $\frac{p_{d s}}{p_{u s}} \geq\left(\frac{2}{k+1}\right)^{\frac{k}{k-1}}$

$\dot{m}=C_{D} A_{v} p_{u s} \sqrt{\left(\frac{k}{R T_{u s}}\right)\left(\frac{2}{k+1}\right)^{\frac{k+1}{k-1}}}$

The values of the discharge coefficients $\left(C_{D}\right)$ are taken from the experimental results presented in [35]. 


\section{Definitions}

The following equation defines the SR, which is the ratio of the NG mass flow rate to the total fuel (NG and diesel) mass flow rate.

$S R=\frac{\dot{m}_{N G}}{\dot{m}_{d}+\dot{m}_{N G}}$

The bsfc, which is defined as the mass flow rate of fuel consumed per unit brake power and is given in units of $\mathrm{g} / \mathrm{kW} . \mathrm{h}$, is calculated based on the mass flow rates of both fuels. A correction is suggested to take into account the variation in the heating values of the fuels [39]. The bsfc is given by:

$b s f c=\frac{\left[\dot{m}_{d}+\dot{m}_{N G}\left(L H V_{N G} / L H V_{d}\right)\right] \times 3600}{B P}$

\section{Validation of the simulation model}

The governing equations from (1) to (27) are applied on the engine processes (intake, compression, fuel injection, combustion, expansion and exhaust). A step-wise solution using Runge-Kutta fourth order method is carried out. For examining the simulation model validity, the model is executed using the engine specifications in [19] at different loads and different SRs. The following figures represent the results at a constant load of $80 \%$ of the full engine load and different SRs. The results of the pressure time diagram inside the engine cylinder are plotted in Figure 1 to Figure 5. The variation of $\mathrm{NO}_{\mathrm{x}}$ and soot emissions with SR is represented in Figure 6 and Figure 7, respectively. It can be concluded from the figures that reasonable agreement is achieved between the simulation and the experimental results and the model is valid for simulating the performance of a dual fuel NG-diesel engine.

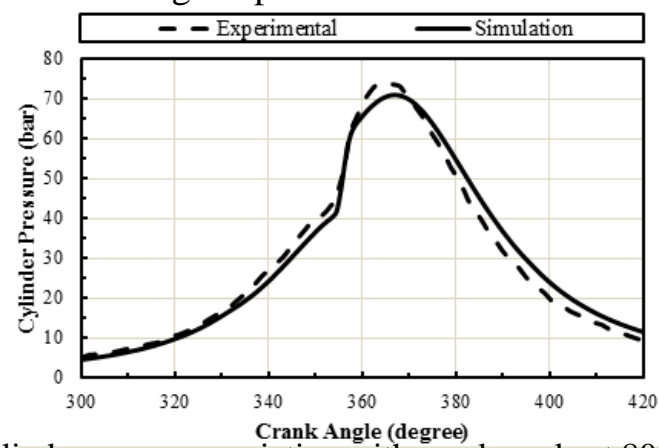

Fig. 1. Cylinder pressure variation with crank angle at $80 \%$ load, $0 \%$ SR

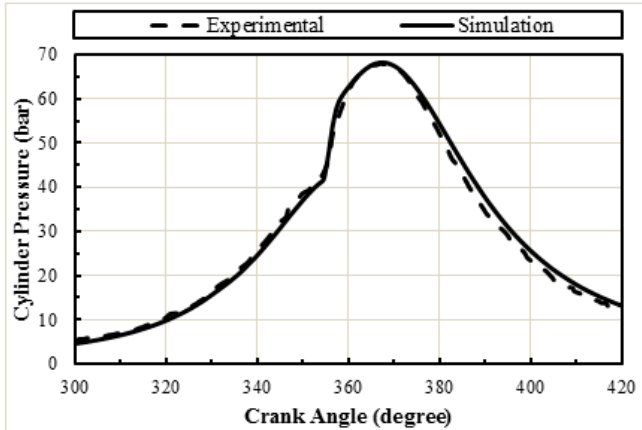

Fig. 2. Cylinder pressure variation with crank angle at $80 \%$ load, $27 \%$ SR 


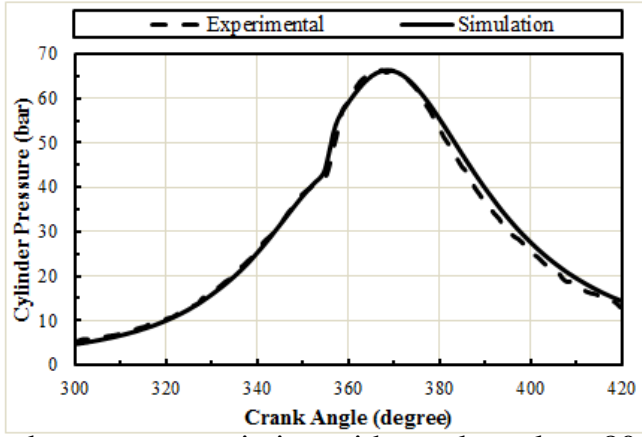

Fig. 3. Cylinder pressure variation with crank angle at $80 \%$ load, $42 \%$ SR

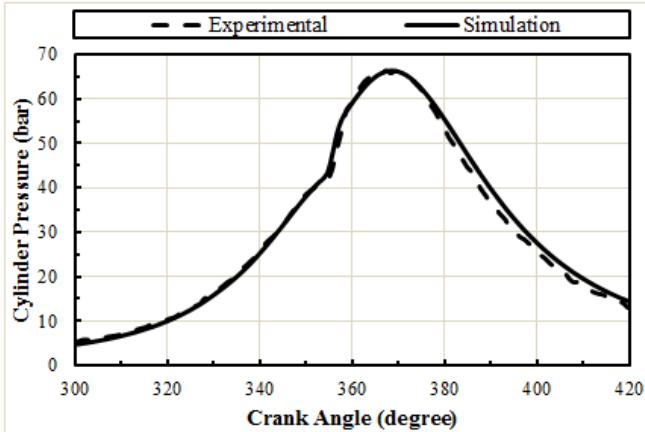

Fig. 4. Cylinder pressure variation with crank angle at $80 \%$ load, 56\% SR

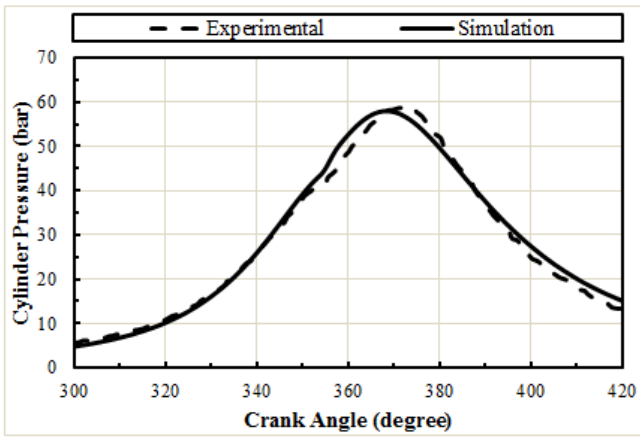

Fig. 5. Cylinder pressure variation with crank angle at $80 \%$ load, $91 \%$ SR

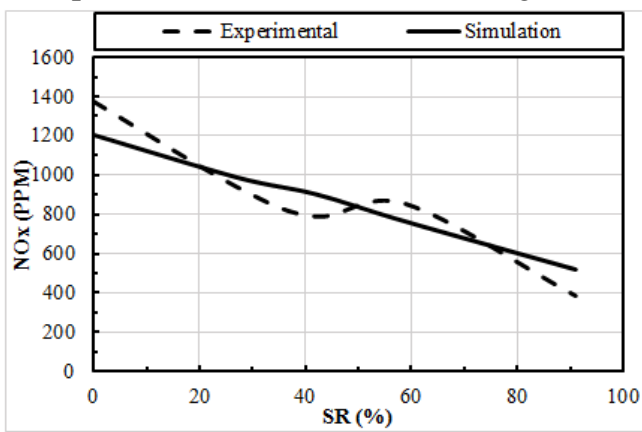

Fig. 6. NOx emissions variation with SR at $80 \%$ load 


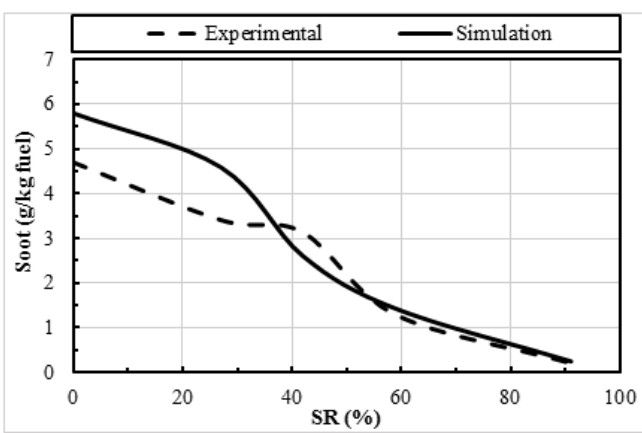

Fig. 7. Soot emissions variation with SR at $80 \%$ load

\section{Engine specifications}

The engine used in the current simulation analyses is HELWAN M114 diesel engine manufactured by Helwan Diesel Engines Company, Factory 909. The main engine specifications are listed in Table 1. A schematic of the combustion chamber of the engine showing the location of the NG injector for the proposed technique is given in Figure 8.

\section{Natural gas composition}

The NG composition used in this analysis is taken as the composition of the NG produced from Abu Madhi field which is an Egyptian field located in the Nile delta [40]. The data of the composition are given in Table 2.

\section{Table 1.}

Main engine specifications used in this study

\begin{tabular}{|l|l|}
\hline Number of cylinders & 4 \\
\hline Cylinder bore & $112 \mathrm{~mm}$ \\
\hline Stroke & $115 \mathrm{~mm}$ \\
\hline Compression ratio & 16.4 \\
\hline Start of diesel fuel injection & $22^{\circ} \mathrm{CA} \mathrm{BTDC}$ \\
\hline Injection duration of diesel fuel & $30^{\circ} \mathrm{CA}$ \\
\hline Intake valve opening & $10^{\circ} \mathrm{CA} \mathrm{BTDC}$ \\
\hline Intake valve closure & $43^{\circ}$ CA ABDC \\
\hline Exhaust valve opening & $43^{\circ} \mathrm{CA}$ BBDC \\
\hline Exhaust valve closure & $10^{\circ} \mathrm{CA}$ ATDC \\
\hline Intake valve head diameter & $49.5 \mathrm{~mm}$ \\
\hline Exhaust valve head diameter & $42 \mathrm{~mm}$ \\
\hline Maximum lift of valves & $12.3 \mathrm{~mm}$ \\
\hline
\end{tabular}

Table 2.

NG composition used in this study

\begin{tabular}{|c|c|}
\hline Component & Volume (\%) \\
\hline Methane & 92.766 \\
\hline Ethane & 4.117 \\
\hline Propane & 1.211 \\
\hline Carbon dioxide & 0.688 \\
\hline Nitrogen & 0.385 \\
\hline
\end{tabular}




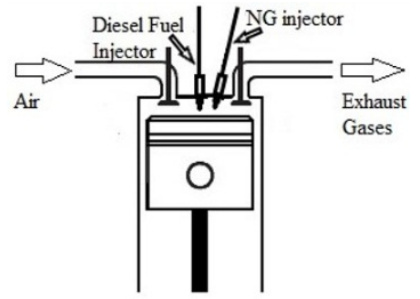

Fig. 8. A schematic of the combustion chamber of the engine showing the location of the NG injector for the proposed technique

\section{Results and discussion}

Figure 9 represents a comparison between the cylinder pressure variation with crank angle for EDI and IMI techniques at 40\% SR and 90\% SR and at a constant speed of 2000 rpm. The fuel-air ratio is kept constant for the two techniques at the same SR value. It can be noticed that the pressure profile for the EDI technique is higher than that of the IMI technique at the same fuel-air ratio. This can be referenced to the difference in the volumetric efficiency values for the two techniques at the same conditions. The volumetric efficiency of the EDI technique is higher as the engine inducts air only while in the IMI technique it inducts air-NG mixture which reduces the inducted amount of air due to the displacement of the in-cylinder air by the NG. Therefore, more amount of fuel can be injected using the EDI technique at the same fuel-air ratio which results in higher pressure profile as shown in the figure. The corresponding values of volumetric efficiency, brake power and brake thermal efficiency are tabulated in Table 3 at 40\% SR and 90\% SR. It can be found that using EDI technique results in a percentage increase in the brake power of $3.8 \%$ and $8.7 \%$ at $40 \%$ SR and $90 \%$ SR, respectively compared to the use of IMI technique.

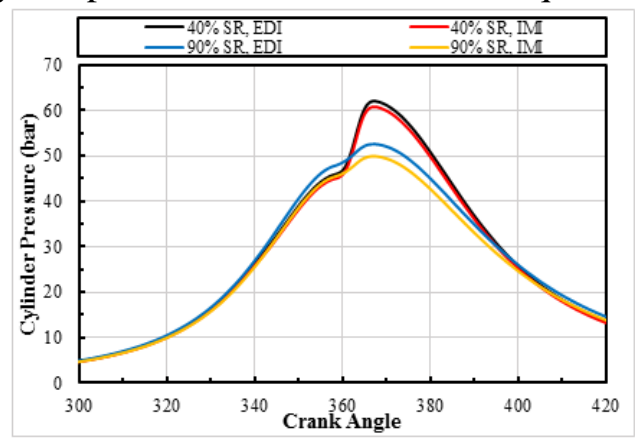

Fig. 9. Cylinder pressure variation with crank angle using EDI and IMI techniques

Table 3.

Comparison between the performance results of IMI and EDI techniques

\begin{tabular}{|c|c|c|c|c|c|c|}
\hline \multirow{2}{*}{ Technique } & \multicolumn{3}{|c|}{$40 \%$ SR } & \multicolumn{3}{c|}{$90 \%$ SR } \\
\cline { 2 - 7 } & $\eta_{\mathrm{v}}(\%)$ & $\mathrm{BP}(\mathrm{kW})$ & $\eta_{\text {bth }}(\%)$ & $\eta_{\mathrm{v}}(\%)$ & $\mathrm{BP}(\mathrm{kW})$ & $\eta_{\text {bth }}(\%)$ \\
\hline IMI & 91.4 & 43.08 & 34.41 & 88.6 & 41.12 & 32.58 \\
\hline EDI & 93.3 & 44.7 & 34.7 & 93.3 & 44.7 & 33.32 \\
\hline
\end{tabular}

In order to evaluate the effects of variations in load and SR on the engine performance using EDI technique, results were obtained from the model at a constant speed of 2000 rpm. The SR was varied from $0 \%$ to $90 \%$. Increasing the SR above $90 \%$ may lead to misfire since it results in low ignition energy for the NG-air mixture from the combustion 
Muhammad Abdulmoez et al., Simulation modeling of a dual fuel (natural gas-diesel) engine ........

of low amount of diesel fuel [11,19]. The engine load was varied from a low load of 20 $\mathrm{kW}$ to the full engine load which equals $44.7 \mathrm{~kW}$ (60 hp).

Figure 10 illustrates the variation of the cylinder pressure with crank angle at full load and different SRs. During the compression stroke, increasing the SR results in increase in the cylinder contents mass since NG is injected after IVC. The increase in mass results in a slight increase in pressure during the compression stroke. The NG has a low laminar flame speed, therefore, increasing the SR ratio reduces the fuel burning rate which reduces the pressure rise rate through the engine cylinder. Moreover, the piston downward movement through the expansion stroke leads to further decrease in the cylinder pressure. This can be noticed in Figure 10 at SRs $0 \%$ to $90 \%$. The same trend of the pressure variation with SR is also noticed in the temperature variation as shown in Figure 11 for the same discussed reasons.

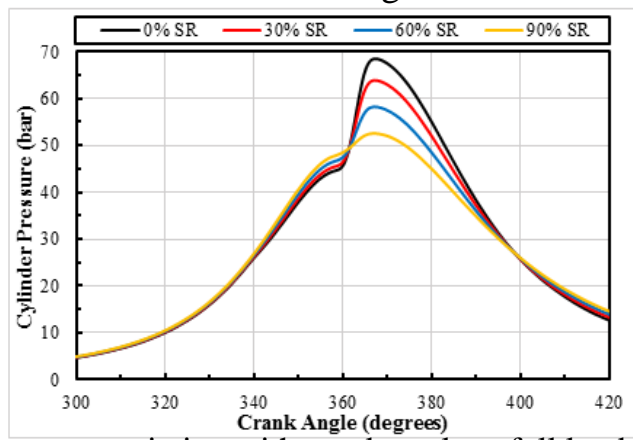

Fig. 10. Cylinder pressure variation with crank angle at full load and using different SRs

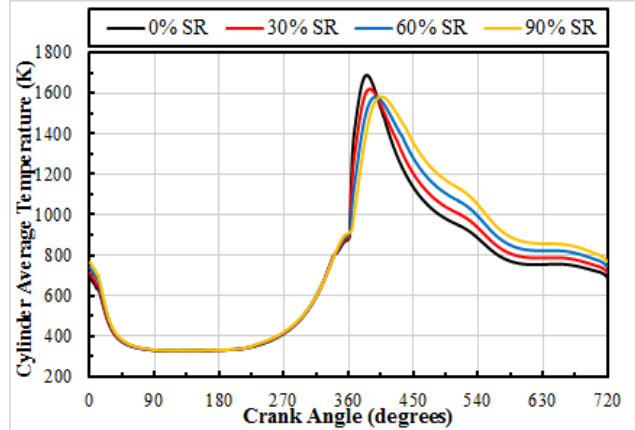

Fig. 11. Cylinder temperature variation with crank angle at full load and using different SRs

Figure 12 represents the temperature variation of the burned and unburned zones besides the average temperature at $0 \%$ SR and $90 \%$ SR. It can be noticed that the burned zone temperature using $90 \%$ SR is slightly higher than the of $0 \%$ SR since the LHV of NG is $48556 \mathrm{~kJ} / \mathrm{kg}$ (based on the used composition) while it is $43400 \mathrm{~kJ} / \mathrm{kg}$ for diesel. The unburned zone temperature using $90 \%$ SR is lower than that using $0 \%$ SR due to the low flame speed of the NG which allows the downward piston movement effect to reduce its temperature. The average temperature profile of the in-cylinder content has a slow rise rate at $90 \% \mathrm{SR}$ as shown in the figure due to the slow burning rate of the NG. 


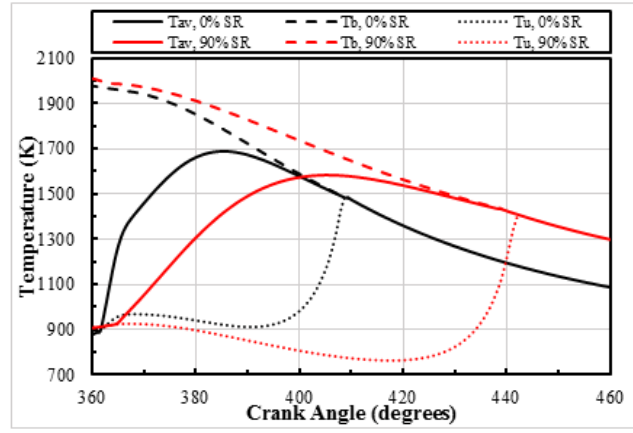

Fig. 12. Burned, unburned, and average cylinder temperatures variation with crank angle at $0 \%$ SR and $90 \%$ SR

Figure 13 represents the variation of cylinder maximum pressure with load using different SRs. With increasing load, the cylinder maximum pressure increases due to the increase of the fuel amount and hence the released energy from the fuel during the combustion process. The maximum pressure increases from 58.3 bar to 68.5 bar at $0 \% \mathrm{SR}$ with a percentage increase of $17.5 \%$ through the load range. At $90 \% \mathrm{SR}$, the same corresponding values are 50.2 bar, 52.6 bar with a percentage increase of $4.8 \%$. The maximum pressure decreases with increasing SR at the same load due to the low burning rate of NG as discussed previously. where it can be noticed that it decreases from 68.5 bar at $0 \%$ SR to 52.6 bar at $90 \%$ SR at full load. This suggests that the diesel fuel injection, which initiates the combustion, should be advanced with increasing SR.

Figure 14 shows that the maximum cylinder temperature increases with increasing load due to the increase of fuel amount as mentioned above. It increases from $1313 \mathrm{~K}$ to 1689 $\mathrm{K}$ at $0 \%$ SR with a percentage increase of $28.6 \%$ through the load range. It also, increase from $1191 \mathrm{~K}$ to $1583 \mathrm{~K}$ at $90 \%$ SR with a percentage increase of 32.9\%. Moreover, the maximum temperature decreases with increasing SR at the same load due to the slow burning rate of NG where it decreases from $1689 \mathrm{~K}$ at $0 \%$ SR to $1583 \mathrm{~K}$ at $90 \%$ at the full load condition. The slow burning rate of NG increases the time available for heat transfer through cylinder walls and, therefore, the heat transfer rate increases which produce further reduction in the maximum cylinder temperature.

The brake thermal efficiency of the engine increases with the load as shown in Figure 15 due to the increase in maximum cylinder temperature. It increases from $30.6 \%$ to $36.8 \%$ at $0 \%$ SR with a value of $6.2 \%$ through the load range and it increases from $27.9 \%$ to $33.3 \%$ with an increment of $5.4 \%$ at $90 \%$ SR at the same load range. The brake thermal efficiency decreases with increasing SR at the same load where it decreases from $36.8 \%$ at $0 \%$ SR to $33.3 \%$ at $90 \%$ SR at full load condition. These trends in the brake thermal efficiency follow the same previous trends in the maximum pressure and temperature. It can be noticed from Figure 14 that the maximum temperature curves converge at high SRs starting from 50\% SR and this convergence is reflected on the brake thermal efficiency curves in Figure 15. 
Muhammad Abdulmoez et al., Simulation modeling of a dual fuel (natural gas-diesel) engine ........

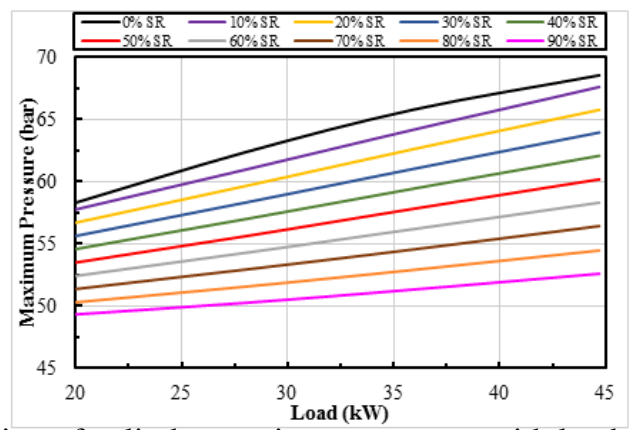

Fig. 13. Variation of cylinder maximum pressure with load using different SRs

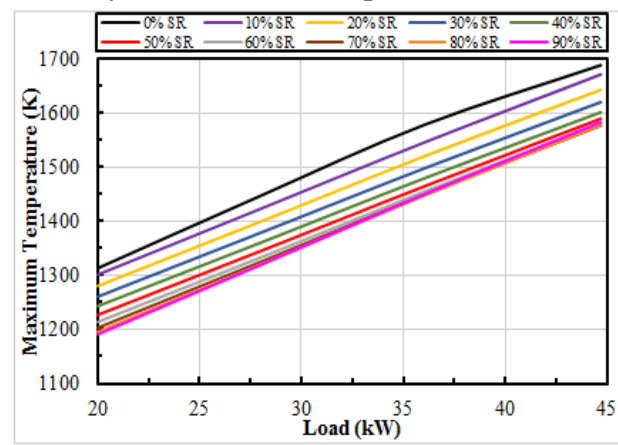

Fig. 14. Variation of cylinder maximum temperature with load using different SRs

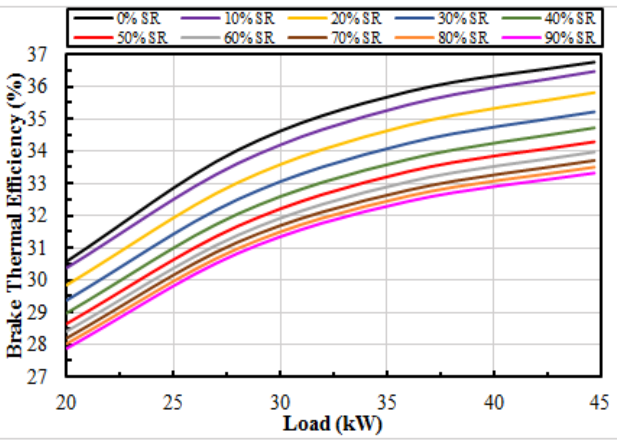

Fig. 15. Variation of brake thermal efficiency with load using different SRs

Because of the increase in brake thermal efficiency with the load, the bsfc decreases as can be seen in Figure 16. The bsfc decreases from $271 \mathrm{~g} / \mathrm{kW}$.h to $226 \mathrm{~g} / \mathrm{kW} . \mathrm{h}$ at $0 \%$ SR with a percentage reduction of $16.6 \%$ through the load range. At $90 \% \mathrm{SR}$, it decreases from $297 \mathrm{~g} / \mathrm{kW}$.h to $249 \mathrm{~g} / \mathrm{kW}$.h with a percentage reduction of $16.2 \%$ following the reverse trend of the brake thermal efficiency. At full engine load, the bsfc increased with a percentage of $10.2 \%$ when the SR was increased from 0\% SR to $90 \%$ SR. The same trend of convergence in the results at high SRs is noticed in Figure 16. 


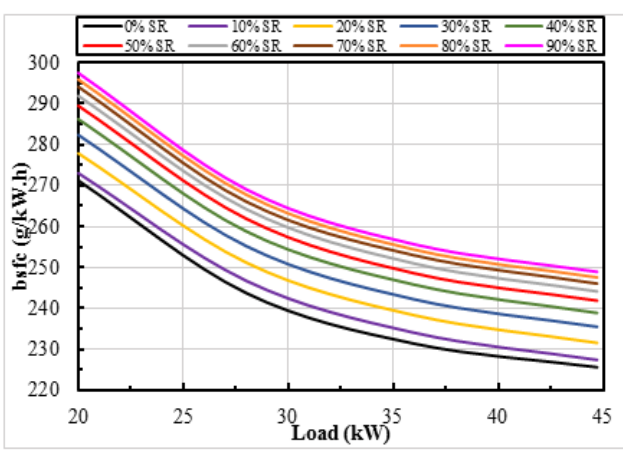

Fig. 16. Variation of bsfc with load using different SRs

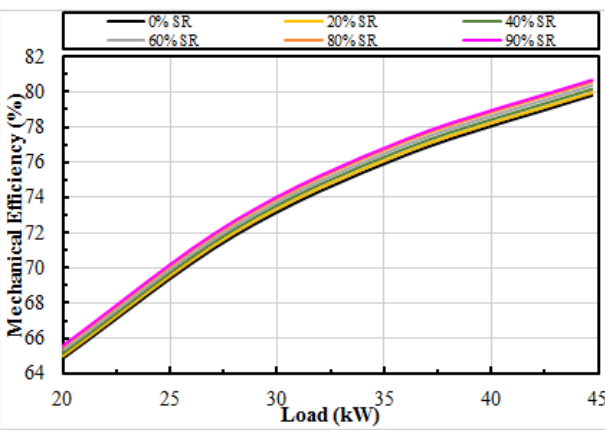

Fig. 17. Variation of mechanical efficiency with load using different SRs

Increasing the engine load by increasing the amounts of injected fuels results in more energy release and hence more rise in the cylinder pressure which increases the indicated power. Also, the friction power increases with the load due to the increased cylinder pressure. The increase in cylinder pressure results in increase in the normal force which pushes the piston rings against the cylinder walls produces higher friction power. However, the increase in the friction power is very small relative to the increase of the indicated power which results in a considerable increment in the brake power and hence in the mechanical efficiency as can be seen in Figure 17. The mechanical efficiency increases from $65 \%$ to $80 \%$ at $0 \%$ SR and from $65.6 \%$ to $80.8 \%$ at $90 \%$ SR. It is noticed that the mechanical efficiency has a slight increase with increasing SR values at the same load due to the corresponding decrease in maximum cylinder pressure values in Figure 13.

The emissions of $\mathrm{NO}_{\mathrm{x}}$ are mainly affected by the cylinder temperature. The higher the temperature the greater the amount of produced $\mathrm{NO}_{\mathrm{x}}$. As indicated in Figure 18, $\mathrm{NO}_{\mathrm{x}}$ emissions increase with increasing engine load due to the increase in cylinder temperature. At low loads, almost zero $\mathrm{g} / \mathrm{kW}$.h of $\mathrm{NO}_{\mathrm{x}}$ are produced even with diesel fuel only $(0 \% \mathrm{SR})$ due to the low temperature level of the cylinder content. Increasing SR values reduces the $\mathrm{NO}_{\mathrm{x}}$ emissions at the same load through the load range. The effect of NG addition on reducing $\mathrm{NO}_{\mathrm{x}}$ emissions is more pronounced at high loads where it decreases from $2.1 \mathrm{~g} / \mathrm{kW} . \mathrm{h}$ at $0 \% \mathrm{SR}$ to $1.5 \mathrm{~g} / \mathrm{kW} . \mathrm{h}$ at $90 \% \mathrm{SR}$ with a percentage reduction of $28.6 \%$ at full load condition.

The main parameter that affects soot emissions when varying load and SR is the amount of diesel fuel as the soot emissions from the NG combustion at lean mixture condition is approximately zero. Increasing the engine load at constant SR means increasing the amount of diesel fuel which in turn increases soot emissions as shown in Figure 19. The soot emissions increase from $1.71 \mathrm{~g} / \mathrm{kW} . \mathrm{h}$ to $2.7 \mathrm{~g} / \mathrm{kW}$.h at $0 \%$ SR with a percentage increase of 
Muhammad Abdulmoez et al., Simulation modeling of a dual fuel (natural gas-diesel) engine ........

$58 \%$ as the fuel is diesel only while it achieved a very little increase from $0.26 \mathrm{~g} / \mathrm{kW}$.h to $0.38 \mathrm{~g} / \mathrm{kW} . \mathrm{h}$ at $90 \%$ SR due to the high percentage of NG. At full engine load, the percentage reduction in soot emissions was $86 \%$ when the SR increased from $0 \%$ SR to $90 \%$ SR.

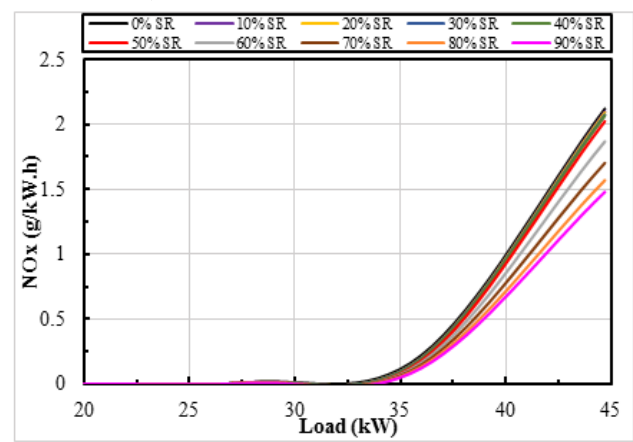

Fig. 18. Variation of NOx emissions with load using different SRs

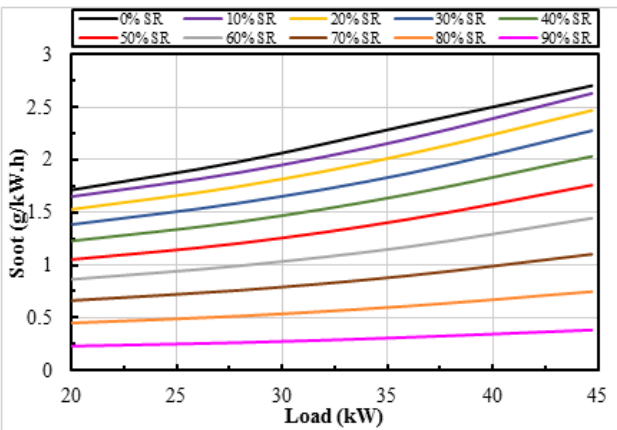

Fig. 19. Variation of soot emissions with load using different SRs

\section{Conclusions}

EDI technique of NG in a dual fuel engine was studied using a two-zone 0-D model. The model is applied to study the performance of HELWAN M-114 diesel engine when operating in dual fuel mode with NG and diesel as a case study. The results are obtained by varying the engine load and the SR. The results can be concluded as follows:

1- The EDI technique results in increase in the volumetric efficiency, the brake power, and the brake thermal efficiency compared to using IMI technique at constant airfuel ratio. The maximum increase in brake power is $8.7 \%$ at $90 \%$ SR and full load.

2- The slow burning rate of NG results in reduction in the maximum cylinder pressure and temperature with increasing the SR through the used load range. A suggested solution is to advance the injection timing of diesel fuel with increasing SR.

3- The brake thermal efficiency decreases with increasing SR due to the decrease in the maximum cylinder temperature. The brake thermal efficiency decreased from $36.8 \%$ at $0 \%$ SR to $33.3 \%$ at $90 \%$ SR at full load condition. This results in an accompanying increase in brake specific fuel consumption form $226 \mathrm{~g} / \mathrm{kW} . \mathrm{h}$ at $0 \%$ SR to $249 \mathrm{~g} / \mathrm{kW} . \mathrm{h}$ at $90 \%$ SR with a percentage increase of $10.3 \%$ at full load.

4- The decrease in the maximum cylinder pressure with increasing the SR leads to a very slight increase in the mechanical efficiency from $80 \%$ at $0 \%$ SR to 80.8 at $90 \%$ SR at full load.

5- The major benefit of increasing the SR is the reductions in $\mathrm{NO}_{\mathrm{x}}$ and soot emissions. However, higher SRs than 50\% SR are required at high loads for substantial decrease in $\mathrm{NO}_{\mathrm{x}}$ and soot emissions to meet the requirements of the emission 
standards. $\mathrm{NO}_{\mathrm{x}}$ emissions decreased from $2.1 \mathrm{~g} / \mathrm{kW}$.h at $0 \% \mathrm{SR}$ to $1.5 \mathrm{~g} / \mathrm{kW} . \mathrm{h}$ at $90 \%$ SR with a percentage reduction of $28.6 \%$ and soot emissions decreased from $2.7 \mathrm{~g} / \mathrm{kW}$.h at $0 \%$ SR to $0.38 \mathrm{~g} / \mathrm{kW}$.h at $90 \%$ SR with a percentage reduction of $86 \%$ at full load condition. This supports the suggestion of applying EDI technique especially at high SRs to reduce $\mathrm{NO}_{\mathrm{x}}$ and soot emissions with higher brake power and brake thermal efficiency compared to using IMI technique.

\section{REFERENCES}

[1] 2018, BP Statistical Review of World Energy, British Petroleum Company.

[2] Semin, and Rosli, A. B., 2008, "A Technical Review of Compressed Natural Gas as an Alternative Fuel for Internal Combustion Engines,” Am. J. Eng. Appl. Sci., 1(4), pp. 302-311.

[3] 2018, Clean Cities Alternative Fuel Price Report, U.S. Department of Energy.

[4] Mokhatab, S., Poe, W. A., and Mak, J. Y., 2015, Handbook of Natural Gas Transmission and Processing: Principles and Practices, Elsevier Inc.

[5] Boretti, A., Lappas, P., Zhang, B., and Mazlan, S. K., 2013, "CNG Fueling Strategies for Commercial Vehicles Engines-A Literature Review,” SAE Tech. Pap. 2013-01-2812.

[6] McAllister, S., Chen, J.-Y., and Fernandez-Pello, A. C., 2011, Fundamentals of Combustion Processes, Springer New York, New York, NY.

[7] Li, M., Zhang, Q., and Li, G., 2016, "Investigation on the Combustion Noise of a Pilot-Ignited DirectInjection Natural-Gas Engine,” Proc. Inst. Mech. Eng. Part D J. Automob. Eng., 230(14), pp. 1942-1957.

[8] McTaggart-Cowan, G., Huang, J., and Munshi, S., 2017, "Impacts and Mitigation of Varying Fuel Composition in a Natural Gas Heavy-Duty Engine,” SAE Int. J. Engines, 10(4), pp. 2017-01-0777.

[9] Hatzipanagiotou, A., Marko, F., Koenig, G., Krueger, C., Wenzel, P., and Koch, T., 2018, "Numerical and Optical Analysis of Heterogeneous Gas Combustion with Diesel Pilot Ignition in a Commercial Vehicle Engine,” Int. J. Engine Res., 19(1), pp. 109-119.

[10] Liu, J., Zhao, H., Wang, J., and Zhang, N., 2019, “Optimization of the Injection Parameters of a Diesel/Natural Gas Dual Fuel Engine with Multi-Objective Evolutionary Algorithms,” Appl. Therm. Eng., 150(November 2018), pp. 70-79.

[11] Hegab, A., La Rocca, A., and Shayler, P., 2017, "Towards Keeping Diesel Fuel Supply and Demand in Balance: Dual-Fuelling of Diesel Engines with Natural Gas,” Renew. Sustain. Energy Rev., 70, pp. 666-697.

[12] Yeo, J., 2017, "Development of In-Cylinder Fuel Concentration and Pyrometry Optical Diagnostic Tools in Diesel-Ignited Dual-Fuel Natural Gas Engines,” M.A.Sc., University of British Columbia.

[13] Gunawan, H., 1992, "Performance and Combustion Characteristics of a Diesel-Pilot Gas Injection Engine,” M.A.Sc. Thesis, The University of British Columbia.

[14] McTaggart-Cowan, G. P., Mann, K., Huang, J., Wu, N., and Munshi, S. R., 2012, "Particulate Matter Reduction from a Pilot-Ignited, Direct Injection of Natural Gas Engine,” ASME 2012 Internal Combustion Engine Division Fall Technical Conference, ASME, Vancouver, BC, p. 427.

[15] Fasching, P., Sprenger, F., and Granitz, C., 2017, "A Holistic Investigation of Natural Gasdiesel Dual Fuel Combustion with Dual Direct Injection for Passenger Car Applications,” Automot. Engine Technol., 2(1), pp. 79-95.

[16] Mansour, C., Bounif, A., Aris, A., and Gaillard, F., 2001, "Gas-Diesel (Dual-Fuel) Modeling in Diesel Engine Environment,” Int. J. Therm. Sci., 40(4), pp. 409-424.

[17] Hountalas, D. T., and Papagiannakis, R. G., 2000, "Development of a Simulation Model for Direct Injection Dual Fuel Diesel-Natural Gas Engines,” SAE Tech. Pap. 2000-01-0286.

[18] Hountalas, D. T., and Papagiannakis, R. G., 2001, "A Simulation Model for the Combustion Process of Natural Gas Engines with Pilot Diesel Fuel as an Ignition Source," SAE Technical Paper, SAE International.

[19] Hountalas, D. T., and Papagiannakis, R. G., 2002, "Theoretical and Experimental Investigation of a Direct Injection Dual Fuel Diesel-Natural Gas Engine,” SAE Tech. Pap. 2002-01-0868.

[20] Soylu, S., and Van Gerpen, J., 2004, "Development of Empirically Based Burning Rate Sub-Models for a Natural Gas Engine,” Energy Convers. Manag., 45(4), pp. 467-481. 
[21] Zheng, J., and Caton, J. A., 2012, "Use of a Single-Zone Thermodynamic Model with Detailed Chemistry to Study a Natural Gas Fueled Homogeneous Charge Compression Ignition Engine,” Energy Convers. Manag., 53(1), pp. 298-304.

[22] MIKULSKI, M., WIERZBICKI, S., and PIĘTAK, A., 2015, "Zero-Dimensional 2-Phase Combustion Model in a Dual-Fuel Compression Ignition Engine Fed with Gaseous Fuel and a Divided Diesel Fuel Charge,” Maint. Reliab., 17(1), pp. 42-48.

[23] Tirkey, J. V., Gupta, H. N., and Shukla, S. K., 2010, "Integrated Gas Dynamic Computational Modelling and Thermodynamic Combustion Diagnostics of Multicylinder Four-Stroke Spark Ignition Engine Using Compressed Natural Gas as a Fuel,” Int. J. Sustain. Energy, 29(2), pp. 59-75.

[24] Rakopoulos, C. D., Hountalas, D. T., Tzanos, E. I., and Taklis, G. N., 1994, "A Fast Algorithm for Calculating the Composition of Diesel Combustion Products Using 11 Species Chemical-Equilibrium Scheme,” Adv. Eng. Softw., 19(2), pp. 109-119.

[25] Mcbride, B., Gordon, S., and Reno, M., 1993, Coefficients for Calculating Thermodynamic and Transport Properties of Individual Species.

[26] Chen, S. K., and Flynn, P. F., 1965, "Development of a Single Cylinder Compression Ignition Research Engine,” SAE Tech. Pap. 650733.

[27] Grimaldi, C. N., Poggiani, C., Cimarello, A., De Cesare, M., and Osbat, G., 2015, “An Integrated Simulation Methodology of Thermal Management Systems for the CO2 Reduction after Engine Cold Start,” SAE Tech. Pap. 2015-01-0343.

[28] Lawton, B., 1987, "Effect of Compression and Expansion on Instantaneous Heat Transfer in Reciprocating Internal Combustion Engines,” Proc. Inst. Mech. Eng. Part A Power Process Eng., 201(31), pp. 175-186.

[29] Abou Al-Sood, M. M., Ahmed, M., and Abdel-Rahim, Y. M., 2012, "Rapid Thermodynamic Simulation Model for Optimum Performance of a Four-Stroke, Direct-Injection, and VariableCompression-Ratio Diesel Engine,” Int. J. Energy Environ. Eng., 3(1), p. 13.

[30] Taha, Z., Rahim, M. F. A., and Mamat, R., 2017, "Injection Characteristics Study of HighPressure Direct Injector for Compressed Natural Gas (CNG) Using Experimental and Analytical Method,” IOP Conf. Ser. Mater. Sci. Eng., 257(1).

[31] Xu, S., Anderson, D., Hoffman, M., Prucka, R., and Filipi, Z., 2017, “A Phenomenological Combustion Analysis of a Dual-Fuel Natural-Gas Diesel Engine,” Proc. Inst. Mech. Eng. Part D J. Automob. Eng., 231(1), pp. 66-83.

[32] Watson, N., Pilley, A., and Marzouk, M., 1980, “A Combustion Correlation for Diesel Engine Simulation,” SAE Pap. 800029.

[33] Caton, J. A., 2001, "Comparisons of Instructional and Complete Versions of Thermodynamic Engine Cycle Simulations for Spark-Ignition Engines,” Int. J. Mech. Eng. Educ., 29(4), pp. 283-306.

[34] Caton, J. A., 2015, An Introduction to Thermodynamic Cycle Simulations for Internal Combustion Engines, John Wiley \& Sons, Chichester, UK.

[35] Heywood, J. B., 1988, Internal Combustion Engine Fundamentals, McGraw-Hill, New York.

[36] Liu, Y., 2001, "Development of a Phenomenological Cycle Simulation for a Natural Gas Fueled, Compression Ignited, Internal Combustion Engine,” Ph.D. Thesis, University of Alabama.

[37] Hiroyasu, H., Kadota, T., and Arai, M., 1983, "Development and Use of a Spray Combustion Modeling to Predict Diesel Engine Efficiency and Pollutant Emissions, Part 1: Combustion Modeling,” Bull. JSME, 26(214), pp. 569-575.

[38] Faghani, E., and Rogak, S. N., 2012, "Phenomenological Simulation of Non-Premixed Gas Jet Flames Including Soot Formation and Oxidation,” ASME 2012 Internal Combustion Engine Division Fall Technical Conference, ICEF 2012, pp. 803-811.

[39] Egúsquiza, J. C., Braga, S. L., and Braga, C. V. M., 2009, "Performance and Gaseous Emissions Characteristics of a Natural Gas/Diesel Dual Fuel Turbocharged and Aftercooled Engine,” J. Brazilian Soc. Mech. Sci. Eng., 31(2), pp. 142-150.

[40] El-Sherif, a. S., 1998, "Effects of Natural Gas Composition on the Nitrogen Oxide, Flame Structure and Burning Velocity under Laminar Premixed Flame Conditions,” Fuel, 77(14), pp. 1539-1547. 


\title{
نموذج محاكي لمحرك مزدوج الوقود (غاز طبيعي - ديزل) \\ باستخام تقنية الحقن المباشر المبكر للغاز الطبيعي ـ ديزي
}

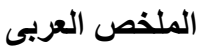

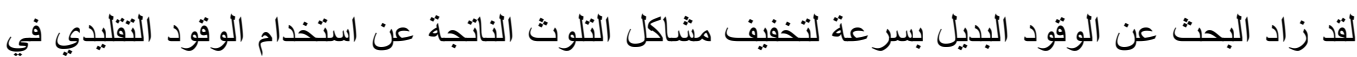

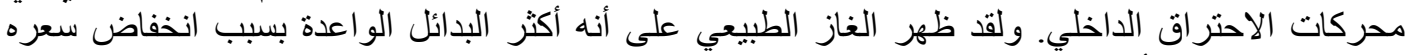
وتو افره في مختلف أنحاء الآعالم.

في هذا البحث، تم تطوير نموذج ثنائي المناطق صفري البعد لمحاكاة المحرك المزدوج الوقود المئر (الغاز

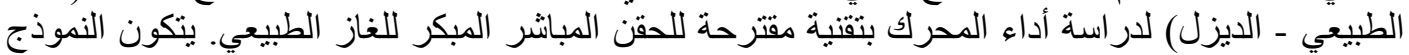

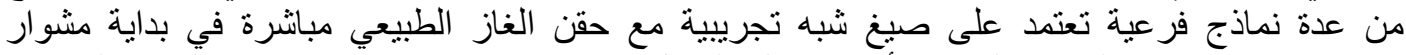

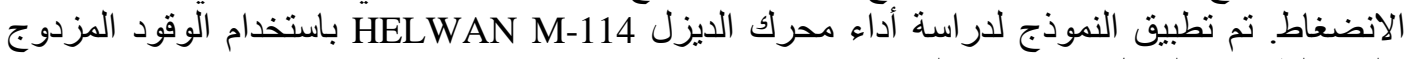

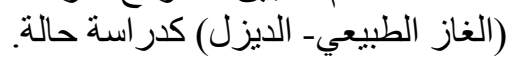

تشير النتائج إلى أن استخدام تقنية الحقن المباثر المبكر للغار الطبيعي (EDI) يؤدي إلى زيادة الكفاءة

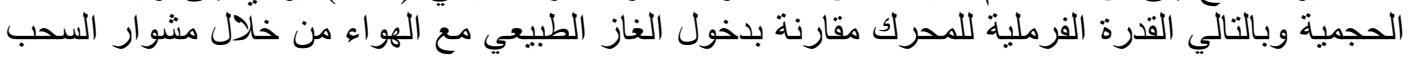

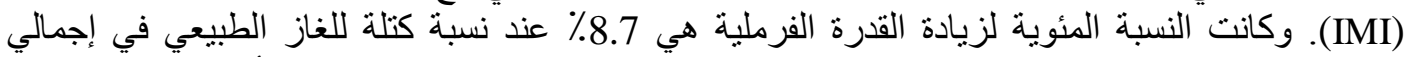
الوقود (SR) هي 90٪ عند الحمل الكامل. لتقييم التقنية المقترحة تم تشغيل النموذج عند عند أحمال ونسب (SR)

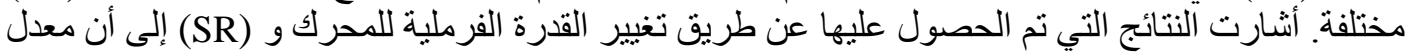

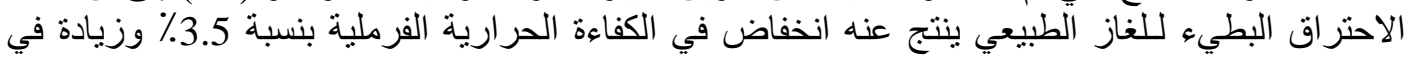

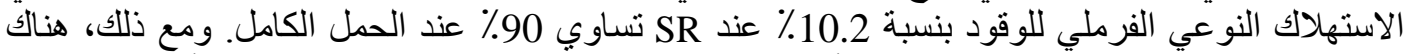

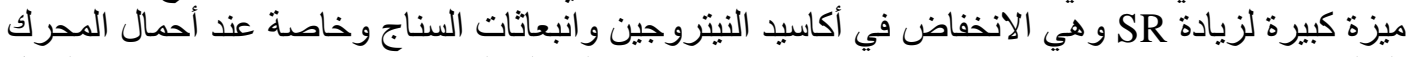

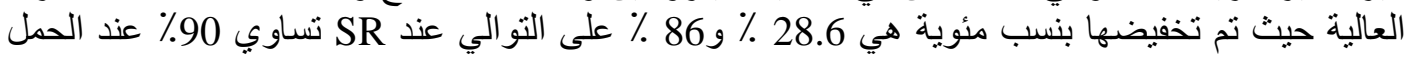

